\title{
Revision of two species of Calligonum from the desert of Xinjiang, Northwestern China
}

\author{
Ying FENG*, BoRong PAN, GuanMian SHEN \\ Xinjiang Institute of Ecology and Geography, Chinese Academy of Sciences, Urumqi 830011, China
}

\begin{abstract}
By examination of Calligonum pumilum A. Los. and Calligonum ruoqiangense Liou f., collected from natural habitats, and the analysis of their variance, this paper revealed that the morphological characters of these specimens are quite different from each other, especially in the twist direction of ribs on fruits, rows of bristles along each rib, rigidity, interweaving degree of bristles, and their geographical distribution. Therefore, it is suggested that $C$. pumilum and $C$. ruoqiangense should be considered as two independent species.
\end{abstract}

Keywords: Calligonum pumilum; Calligonum ruoqiangense; classification; desert; Xinjiang

\section{Introduction}

Calligonum L. is an ancient genus of the arid desert flora, which has its origin in Central Asia. China represents the most eastern part of the distribution range of this species. Calligonum L. has been playing a key role in the stability of the natural and planting vegetation ecosystems of the desert of the Northern China. The species belonging to this genus have great potential and importance because of providing different products and services, such as forage, traditional medicines, arresting desert encroachment and stabilizing sand dunes. Therefore, the genus has attracted the attention of the scientists.

One hundred and seventeen (117) species of Calligonum L. were first recorded by Nikolai in 1936 which were merged to 45 species by Nabiyev in 1971, while further merged by Valovich and Soskov to 26 species in 1973. Wu (1991) claimed that there are 80 species of Calligonum L. in the world, with more than 20 species in China, while 19 species in Xinjiang which occupies $82.6 \%$ of the total species in China. Since, among all species of Calligonum L. found in China, 5 species are endemic to Xinjiang, therefore, it is very important to determine their exact taxonomic status. In "Flora Xinjiangensis", Mao (1996) mentioned that there are 25 species of Calligonum L. in China, while 22 out of these are found in Xinjiang, including C. ruoqiangense Liou f. (Liu, 1985). Thereafter, Mao (1998) stated that 23 species of Calligonum
L. are listed in "Flora Reipublicae Popularis Sinicae", with 4 species indicated as endemic to Xinjiang. However, C. ruoqiangense was not mentioned. In "Plantae Asiae Centralis and Flora of China", Bao and Grabovskaya-Borodina (2003) recognized 23 species of Calligonum L. that are found in China. C. ruoqiangense and C. pumilum were, however, merged together as one species. These reveal that there is high controversy about the taxonomy of various species of Calligonum L. The taxonomy of different species of Calligonum L. is mainly based on the morphological characters of their fruits, which is obviously difficult because of the similarity of morphological characters of fruits, such as the variable twist direction of ribs on fruits, rows of bristles along each rib, width and depth of grooves, rigidity, and interweaving degree of bristles. Since the previous studies on Calligonum L. were contained only in the flora edition, with insufficient taxonomic information with similar and unclear descriptions of some of the species, therefore, it was deemed urgent to improve upon the taxonomy of various species of Calligonum L. review

\section{Materials and methods}

The study was carried out with the help of literature

Received 2010-02-02, accepted 2010-04-06

doi: 10.3724/SP.J.1227.2010.00231

* Corresponding author: Ying FENG (E-mail: luckfy@ms.xjb.ac.cn) 
and examination of herbarium specimens of C. ruoqiangense (Fig. 1a) and C. pumilum (Fig. 1b), which are stored in only three herbariums in China. After carrying out the field investigations and comparing the morphological characters of the two kinds of fruits, it was revealed that these are two significantly different species, and may thus be taken as individual species, with a need for independent description of the two species.
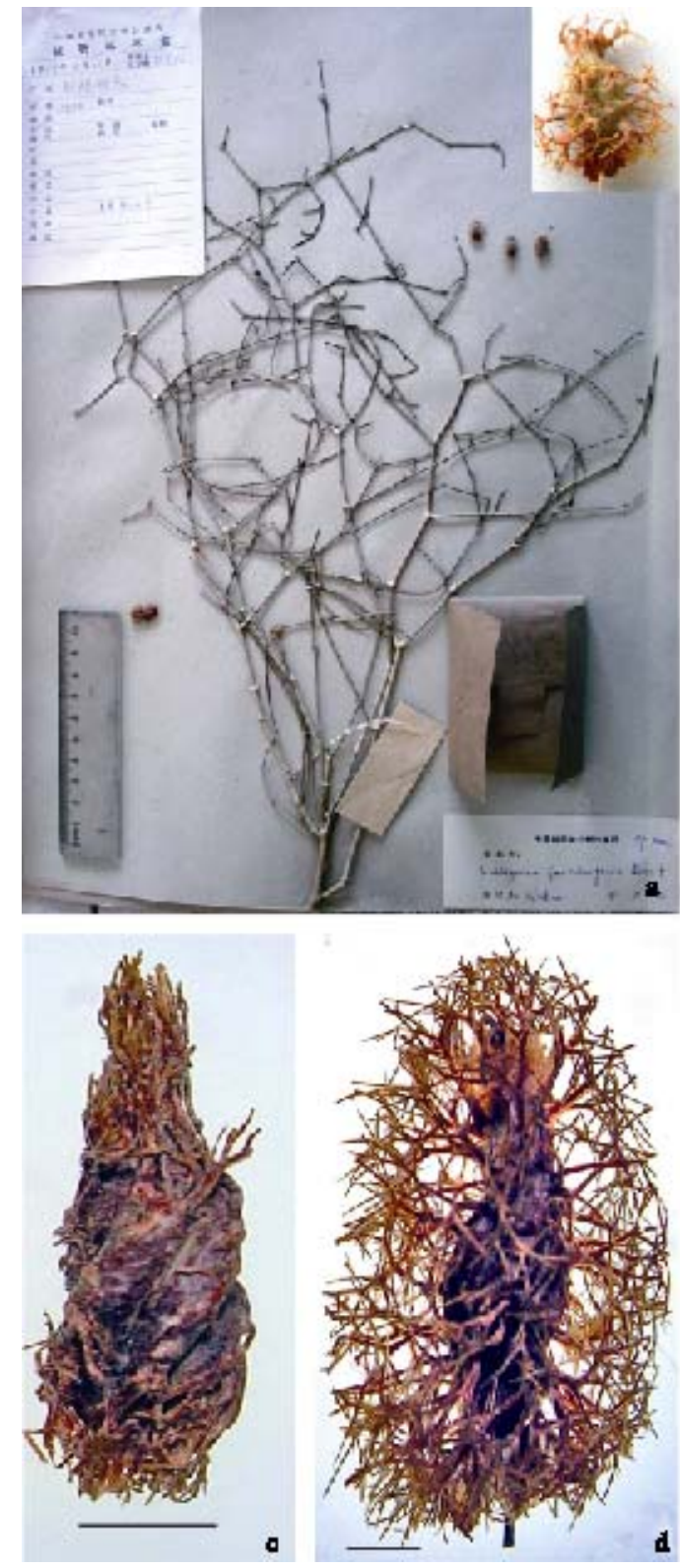

\subsection{Comparison of the microscopic morphological characters and data analysis}

Ten ripe fruits of $C$. pumilum and $C$. ruoqiangense were collected from the field during the growth period of May to August in 2005 and 2006. The microscopic morphological characters of these fruits were examined and compared with the fruits of the specimens from 3 herbariums (LZD, PE and XJBI) under an anatomical microscope with three replicates. The fruit
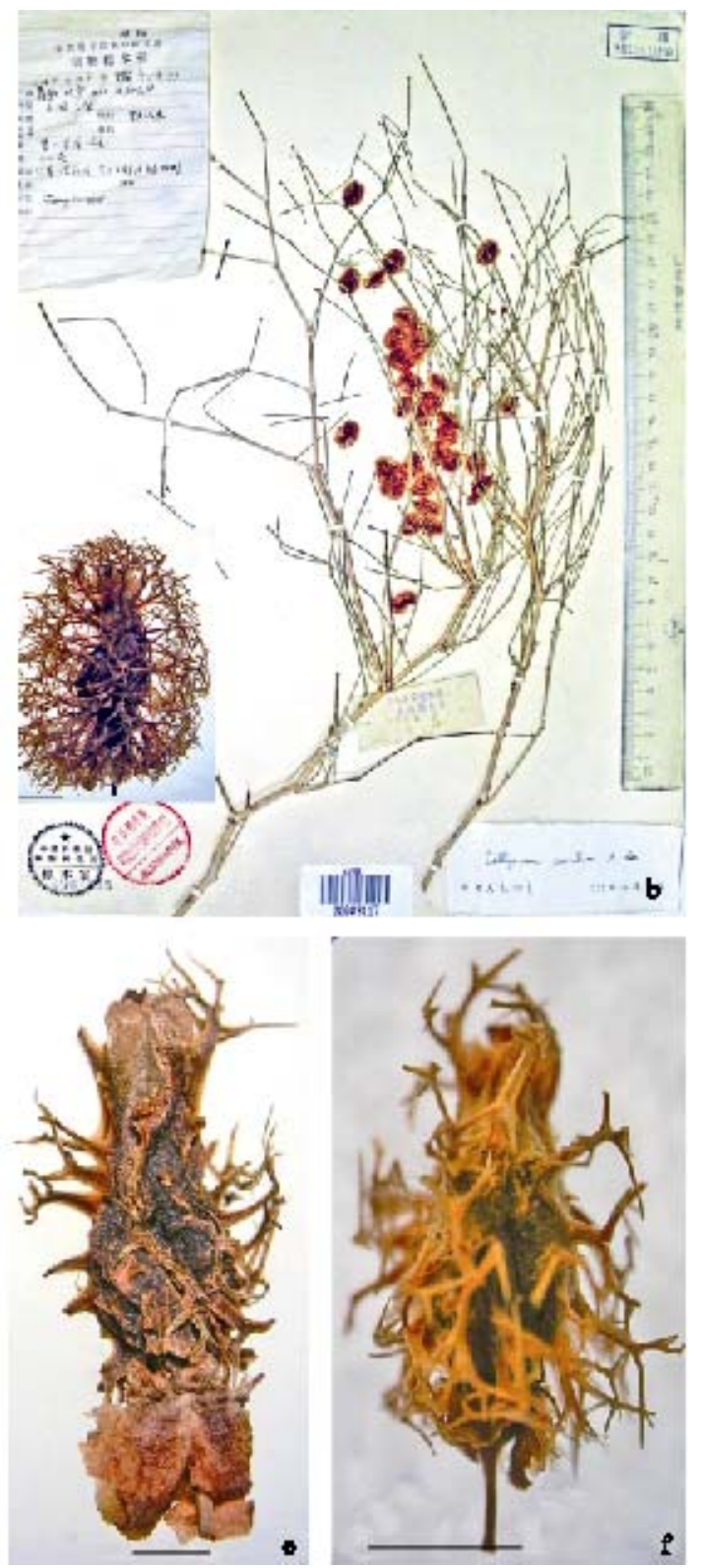

Fig. 1 Holotype and fruits of Calligonum pumilum and Calligonum ruoqiangense

a Holotype of C.ruoqiangense Liou f.; b Holotype of C. pumilum A. Los.; c C. pumilum fruit: on which the ribs twist rightward; d C. pumilum fruit: on which there is 1 row of dense bristles along each rib; e C. ruoqiangense fruit: on which the ribs are twisted leftward; $C$. ruoqiangense fruit: on which there are 1 or 2 rows of sparse rigid bristles along each rib. 
sizes were first measured; the fruits were then immersed in warm water for 5 min to remove the bristles on fruits. The twist directions of the ribs and the rows of bristles along each rib were then observed under an anatomical microscope, followed by the variance analysis of the recorded data. The photos of the fruits were taken under the anatomical microscope. Information on the habitats and geographical distribution of $C$. pumilum and $C$. ruoqiangense were also recorded.

The observed and measured results of the morphological characters of the fruits of $C$. pumilum and $C$. ruoqiangense are given in Table 1.

\subsection{Comparison of the descriptions of the two species in the floras}

In Flora Xinjiangensis, the description of Calligonum pumilum A. Los., carried out by Mao (1996), is as follows:

Calligonum pumilum A. Los. in Bull. Jard. Bot. Princ. URSS 26: 600. 1927.

C. pumilum A. Los. is a shrub species with the height of $30-40 \mathrm{~cm}$, and its old branches are gray; its leaves are acerose, its flowers are damask, and 2 or 3 flowers bloom fasciately in axillae; its achenes are ovate-oblong and 7-10 $\mathrm{mm}$ in length, the ribs are twisted, and the grooves are deep. There is 1 row of bristles along each rib, and the bristles are thin as hair, brittle and easy to break and interwoven. C. pumilum A. Los. is distributed in the sand-gravel deserts with the elevation of 700-1,500 $\mathrm{m}$ above sea level in the Eastern Xinjiang.

In Flora "Desertis Reipublicae Populorum 1: 312-314. 1985”, the description about Calligonum ruoqiangense Liou f., which was carried out by Liu (1985), is as follows:

C. ruoqiangense Liou $\mathrm{f}$. is a shrub species. The plant height is about $50 \mathrm{~cm}$, and its old branches are yellow-gray; its leaves are squama-shaped, its flowers are damask, with 2 or 3 fasciate flowers in axillae; its achene is ovoid with a length of $8-10 \mathrm{~mm}$, and the ribs are twisted. There is 1-row of bristles along each rib and, sometimes, with 2 incomplete rows, the bristles are very sparse, rigid and easy to break and interwoven. C. ruoqiangense Liou $\mathrm{f}$. is distributed in the sand-gravel deserts and mobile-dune regions with the elevation of 700-1,500 $\mathrm{m}$ above sea level in the Southern Xinjiang.

\section{Results and conclusion}

After the examination of the specimens, it was found that the ribs on fruits of $C$. pumilum were twisted towards right, with one row of bristles along each rib (Fig. 1c); the bristles are thin as hair and interwoven to cover fruits (Fig. 1d). C. pumilum is widely distributed in Yiwu, Hami and Shanshan counties and other places in the Eastern Xinjiang. Therefore, C. pumilum were

Table 1 Morphological characteristics of the fruits of C. pumilum and C. ruoqiangense

\begin{tabular}{|c|c|c|c|c|c|c|}
\hline Species & $\begin{array}{l}\text { Fruit size } \\
\quad(\mathrm{mm})\end{array}$ & $\begin{array}{l}\text { Row of bristles } \\
\text { along each rib }\end{array}$ & Bristle characters & $\begin{array}{l}\text { Twist direc- } \\
\text { tion of ribs }\end{array}$ & $\begin{array}{c}\text { Groovy } \\
\text { width }(\mathrm{mm})\end{array}$ & Voucher Number \\
\hline C. pumilum & $10 \times 15$ & 1 & $\begin{array}{l}\text { Bristles are thin as hair and } \\
\text { interweave }\end{array}$ & $\begin{array}{l}\text { Ribs twist } \\
\text { obviously } \\
\text { rightward. }\end{array}$ & $1-1.10$ & $\begin{array}{c}47521(\mathrm{XJBI}) \\
0067165(\mathrm{XJBI}) \\
47455(\mathrm{PE}) \\
318567(\mathrm{PE} ; \mathrm{XJBI}) \\
05-5-10(\mathrm{XJBI}) \\
05-5-11(\mathrm{XJBI}) \\
06-5-21(\mathrm{XJBI}) \\
06-5-22(\mathrm{XJBI})\end{array}$ \\
\hline C. ruoqiangense & $6 \times 8$ & $1-2$ & $\begin{array}{l}\text { Bristles are wide, rigid and } \\
\text { sparse without twisting }\end{array}$ & $\begin{array}{l}\text { Ribs twist } \\
\text { slightly } \\
\text { leftward. }\end{array}$ & $1-1.15$ & $\begin{array}{c}\text { Exped.111 (holotype, } \\
\text { LZD; isotype, PE) } \\
\text { 05-5-01 (XJBI) } \\
\text { 05-5-02 (XJBI) } \\
\text { 05-5-03 (XJBI) } \\
\text { 06-5-12 (XJBI) } \\
\text { 06-5-13 (XJBI) } \\
\text { 05-5-04 (XJBI) }\end{array}$ \\
\hline $\begin{array}{l}\text { Results of variance } \\
\text { analysis ( } F \text {-values) }\end{array}$ & $2266.5^{* *}$ & $13.50^{* *}$ & & $65535^{* *}$ & $0.57^{\mathrm{NS}}$ & \\
\hline
\end{tabular}

\footnotetext{
Significant differences at ${ }^{* *} P<0.01$ is indicated; ${ }^{\text {NS }}$ indicates no significant difference. $F$-values are shown.
} 
the substituted species of $C$. ruoqiangense in the Eastern Xinjiang. The ribs on the fruits of $C$. ruoqiangense are twisted towards its left (Fig. 1e); there are 1-2 rows of bristles along each rib. The bristles are sparse without twisting (Fig. 1f). C. ruoqiangense is distributed in Ruoqiang County in the Southern Xinjiang only. The results revealed that the morphological characters of these two species are significantly different from each other, and could thus easily be distinguished. There is a special difference in the number of rows of bristles on the fruits, one row, or two rows, while the bristles along each rib are twisted either to its left or right. The geographical distribution of the two species is also different. Obviously, C. pumilum and $C$. ruoqiangense are two different species. Based on the results of the macro- and micro-morphological characters of the fruits of $C$. pumilum and C. ruoqiangense and the statistical results, we support the viewpoint of Liu (1985), that is, C. pumilum and C. ruoqiangense should be the two independent species, with the need to reinstate the independent taxonomic position of $C$. ruoqiangense:

(1) Calligonum pumilum A. Los. in Bull. Jard. Bot. Princ. URSS T. 26: 600. 1927; Liou f. in Fl. Des. Reip. Pop. 1: 314. 1985; Mao in Act. Phytotaxon. Sin. 24: 100. 1986, et in F1. Xinjiang. 1: 272, fig. 83: 2. 1996; Mao in Fl. Reip. Pop. Sin. 25: 128. 1998; Bao and Grabovskaya-Borodina in Fl. China. 5: 328. 2003. Specimens: China. Xinjiang: Shanshan, sand-gravel deserts; alt, 700-1500 m above sea level.

C. pumilum is extensively distributed in Yiwu,

\section{References}

Bao B J, Grabovskaya-Borodina A E, Calligonum L. In: Wu Z Y, Raven P H. Flora of China, Vol.5. Beijing: Science Press; St. Louis: Missouri Botanical Garden Press, 2003. 324-328.

Feng Y. The endemic species and distribution in Xinjiang. Acta Botanica Boreali-Occidentalia Sinica, 2003, 23: 263-273.

Liu Y X. Calligonum L. In: Flora in Desertis Reipublicae Populorum Sinarum, Vol.1. Beijing: Science Press, 1985. 312-314.

Mao Z M. Calligonum L. In: Flora Xinjiangensis, Vol.1. Urumqi: Xinjiang Science, Technology and Public Health Press, 1996. 271-272.

Mao Z M, Pan B R. The classification and distribution of the genus Calligonum L. in China. Acta Phytotaxonomica Sinica, 1988, 24 :
Hami, Shanshan counties and other places in the Eastern Xinjiang, and is endemic to China. Specimens examined (such as Fig. 1b) are as followings: Hami, Xinjiang, China. Qaidam Basin Investigation Team 318567 (PE); from Shanshan to the west of Hami 20 km away, Wang 4586 (PE); northwest from Hami County Town. Chang 0067165 (XJBI); west Shanshan, Pan 47521 (XJBI).

(2) Calligonum ruoqiangense Liou f. in Fl. Des. Reip. Pop. 1: 314. 1985; Mao in Act. Phytotaxon. Sin. 24: 100. 1986, et in F1. Xinjiang. 1: 272, fig. 83:2. 1996; Bao and Grabovskaya-Borodina in Fl. China. 5: 328. 2003. Type: Ruoqiang, Xinjiang, Chain, 1959-6-17, sand-dune regions, East Xinjiang Investigation Team 111 (holotype, LZD; isotype, PE). C. ruoqiangense is endemic to China.

Specimens examined (such as Fig. 1a) are as followings: Ruoqiang, Xinjiang, China. In sand-dune regions, East Xinjiang Investigation Team 111 (holotype, LZD; isotype, PE). 05-5-01 (XJBI), 05-5-02 (XJBI), 05-5-03 (XJBI), 05-5-04 (XJBI), 06-5-12 (XJBI), 06-5-13 (XJBI).

\section{Acknowledgements}

This work was supported by the Province Natural Science Foundation of Xinjiang (0746021001) and the International cooperation projects of ministry of Science and Technology of China (2008DFA31360). We would like to thank the curators of LZD and PE for lending us the specimens and for the permission to examine the specimens.

98-107.

Mao Z M. Calligonum L. In: Flora Reipublicae Popularis Sinicae, Vol.25. Beijing: Science Press, 1998. 126-128.

Nabiyev M. Calligonum L. In: Claves Plantarum Central Asia, Vol.2. Uzbekistan: Science Press, 1971. 123-256.

Nikolai P. Calligonum L. In: Flora SSSR, Vol.5. Moskva: Academii Nauk SSSR, 1936, 538-595.

Valovich E M, Soskov Yu D. The chromosome numbers of species of the genus Calligonum L. Bulletin of Botanical Research, 1973, 58: 554-561.

Wu C Y. The area-types of Chinese genera of seed plants. Acta Botanica Yunnanica, 1991(Suppl.IV): 1-139. 